\title{
Novel biliary stenting with an antireflux system for distal biliary obstruction in a patient with a surgically altered anatomy
}

Prevention of recurrent biliary obstruction (RBO) is important for management of chemotherapy and surgical resection in patients with pancreatobiliary cancers. Placing an antireflux metal stent (ARMS) is generally associated with a reduced risk of RBO and non-occlusion cholangitis compared to using a conventional self-expandable metal stent (SEMS) [1-3]. Recently, a duckbillshaped ARMS was developed, with a design to prevent duodenobiliary reflux [4]. We used a novel ARMS (Duckbill Biliary Stent; Kawasumi Laboratories, Tokyo, Japan) (> Fig. 1) to prevent RBO.

A 71-year-old man who had previously undergone Billroth-II reconstruction after pylorus gastrectomy presented with obstructive jaundice. Computed tomography and magnetic resonance imaging revealed biliary obstruction caused by pancreatic head cancer ( $\triangleright$ Fig.2a, -Fig.2b). We conducted endoscopic retrograde cholangiography using a forward-viewing endoscope and placed a covered SEMS to perform neoadjuvant chemotherapy (NAC). However, this patient experienced early stent occlusion, which caused kinking between the bile duct and stent during chemotherapy ( Fig.3a, \Fig.3b). After removal of the previous stent, a novel ARMS $(10 \mathrm{~mm} \times 6 \mathrm{~cm})$ was safely placed without kinking the bile duct ( $\triangleright$ Video 1 ). NAC continued to be successfully performed from the time of stent exchange until the date of surgery, without any adverse events, including RBO.

A previous study reported that a conventional ARMS was not associated with a longer time to RBO than a covered SEMS [5]. This novel ARMS with excellent flexibility was useful for performing biliary drainage, even in a patient with a strongly flexed bile duct due to surgically altered anatomy.
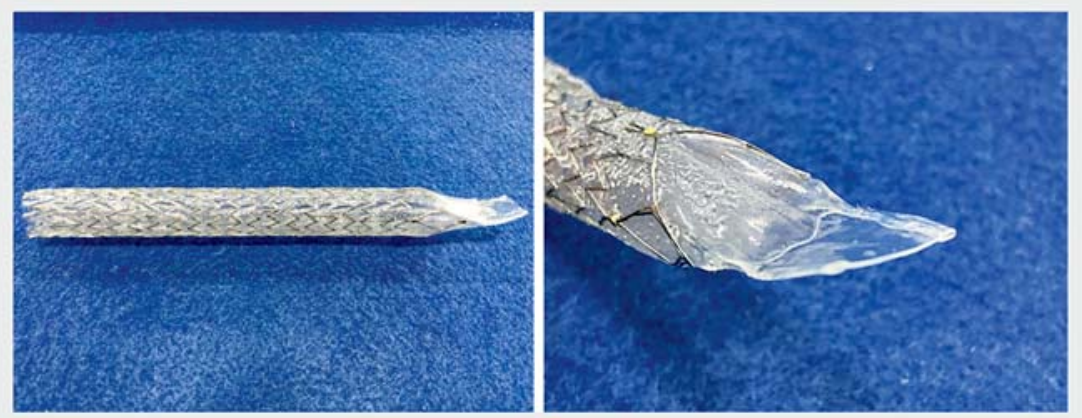

- Fig. 1 Duckbill-shaped anti-reflux metal stent.
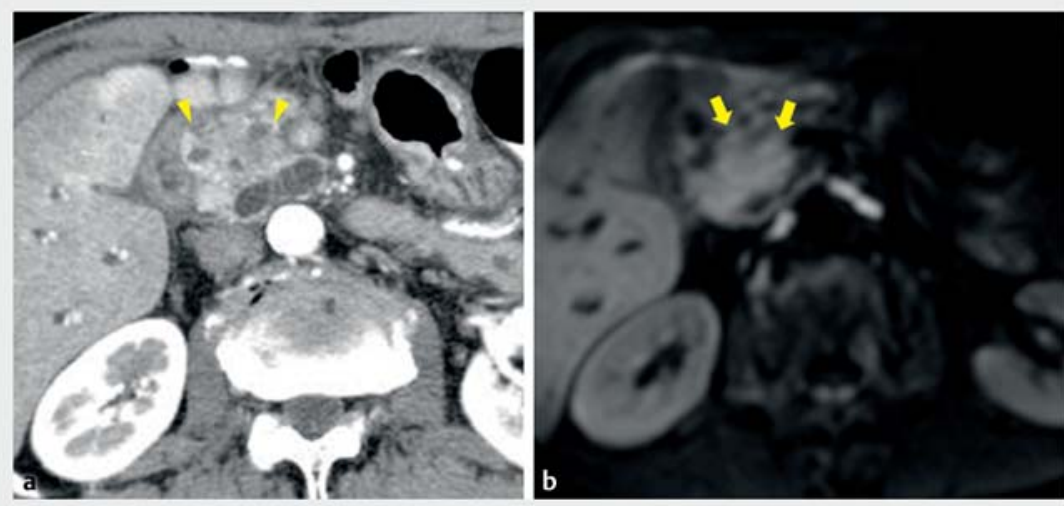

Fig. 2 a Computed tomography shows a hypo or isoattenuated lesion of pancreatic head (yellow arrowhead). b Diffusion-weighted image shows the mass with high signal intensity (yellow arrows).
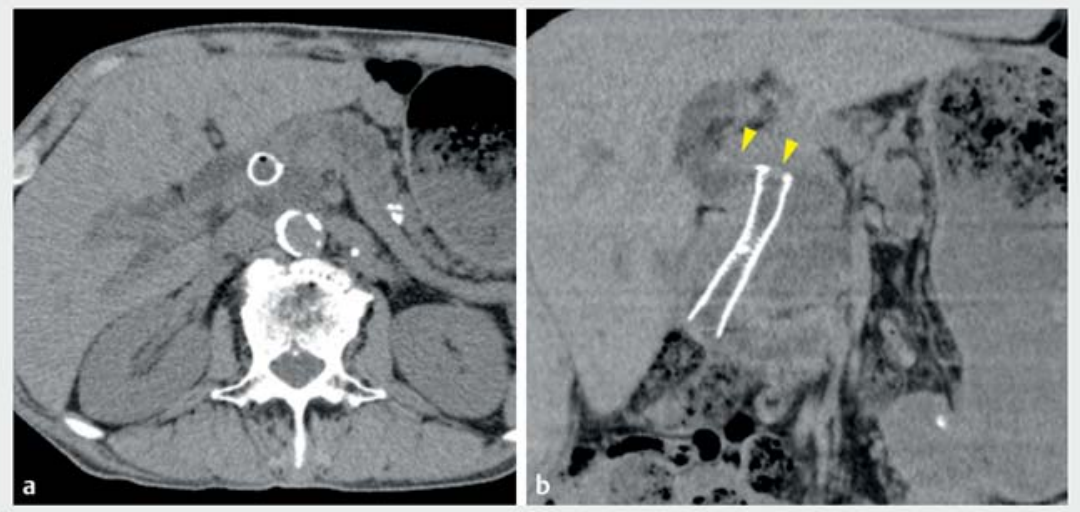

- Fig. 3 a Computed tomography shows stent occlusion due to sludge. $\mathbf{b}$ The common bile duct was kinked by a covered self-expandable metal stent (yellow arrowhead). 


\section{DIDEO}

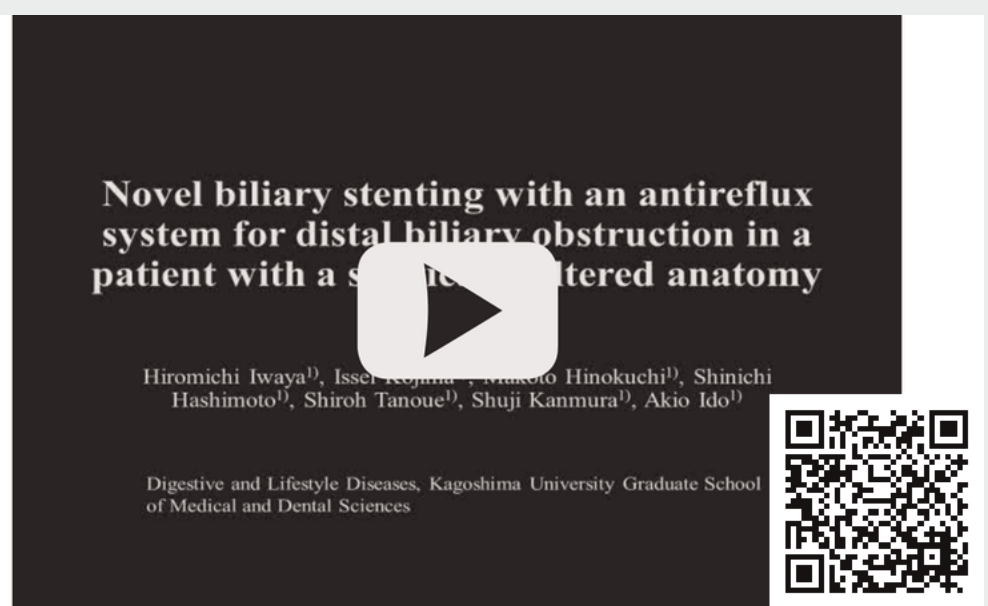

- Video 1 Novel biliary stenting with an antireflux system for distal biliary obstruction in a patient with a surgically altered anatomy.

Competing interests

The authors declare that they have no conflict of interest.

The authors

Hiromichi Iwaya, Issei Kojima, Makoto Hinokuchi, Shinichi Hashimoto, Shiroh Tanoue, Shuji Kanmura, Akio Ido Digestive and Lifestyle Diseases, Kagoshima University Graduate School of Medical and Dental Sciences, Kagoshima, Japan

\section{References}

[1] Hu B, Wang TT, Wu J et al. Antireflux stents to reduce the risk of cholangitis in patients with malignant biliary strictures: a randomized trial. Endoscopy 2014; 46: 120-126

[2] Hamada T, Isayama H, Nakai Y et al. Novel antireflux covered metal stent for recurrent occlusion of biliary metal stents: a pilot study. Dig Endosc 2014; 26: 264-269

[3] Kitano M, Yamashita Y, Tanaka K et al. Covered self-expandable metal stents with an anti-migration system improve patency duration without increased complications compared with uncovered stents for distal biliary obstruction caused by pancreatic carcinoma: a randomized multicenter trial. Am J Gastroenterol 2013; 108: 1713-1722

[4] Kin T, Ishii K, Okabe Y et al. Feasibility of biliary stenting to distal malignant biliary obstruction using a novel designed metal stent with duckbill-shaped anti-reflux valve. Dig Endosc 2020: doi:10.1111/den.13827

[5] Hamada T, Isayama H, Nakai Y et al. Antireflux covered metal stent for nonresectable distal malignant biliary obstruction: Multicenter randomized controlled trial. Dig Endosc 2019; 31: 566-574

\section{Bibliography}

Endosc Int Open 2021; 09: E1561-E1562

DOI 10.1055/a-1512-9758

ISSN 2364-3722

(c) 2021. The Author(s).

This is an open access article published by Thieme under the terms of the Creative Commons Attribution-NonDerivativeNonCommercial License, permitting copying and reproduction so long as the original work is given appropriate credit. Contents may not be used for commercial purposes, or adapted, remixed, transformed or built upon. (https:// creativecommons.org/licenses/by-nc-nd/4.0/)

Georg Thieme Verlag KG, Rüdigerstraße 14, 70469 Stuttgart, Germany

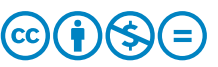

